\section{FRED JENNER HODGES III, MD (1922-2007)}

D r. Fred Jenner Hodges III-known to all as Teddied on August 9, 2007, at his home in Webster Groves, Mo, following treatment for an inoperable brain tumor. Ted was born on September 23, 1922, in Madison, Wis.

His love of the medical field came quite naturally, having been born into a family of physicians. His father, Fred Jenner Hodges II, was professor and chair of the Department of Radiology at the University of Michigan; his uncle, Paul Hodges, was professor and chair of the Department of Radiology at the University of Chicago; and the family's ancestors include Edward Jenner, who developed the smallpox vaccine.

Ted attended the University of California, Berkeley, and the University of Michigan, Ann Arbor. He received an undergraduate degree and a medical degree from the University of Wisconsin, Madison. He completed an internship at Strong Memorial Hospital in Rochester, NY, and a medicine residency and a radiology residency at the University of Michigan, Ann Arbor.

Ted first came to Mallinckrodt Institute of Radiology at Washington University in St. Louis, Mo, in 1957 as an assistant professor. In that same year, Hugh Wilson, the Institute's director, with the assistance of Torgny Greitz, from Sweden, established the neuroradiology section-one of the first in the United States. Ted was named head of the Institute's neuroradiology program in 1958.

During his early years at the Institute, Ted received a National Institutes of Health Fellowship in Neuroradiology and spent 1 year in Gothenburg, Sweden, learning the nuances of this promising subspecialty. He left Mallinckrodt Institute in 1966 to become chief of neuroradiology at Johns Hopkins Hospital in Baltimore, Md, but returned "home" in 1980 as professor of radiology and codirected the Institute's neuroradiology section with Mokhtar Gado. He became professor emeritus in 1993 and officially retired in 2003, closing a career that spanned nearly 6 decades.

Over the years, Ted earned many honors and awards but perhaps none was as dear to his heart as being elected president (1971-1972) of the American Society of Neuroradiology. He was highly respected as a reviewer for the American Journal of Neuroradiology and was a charter member of the Association

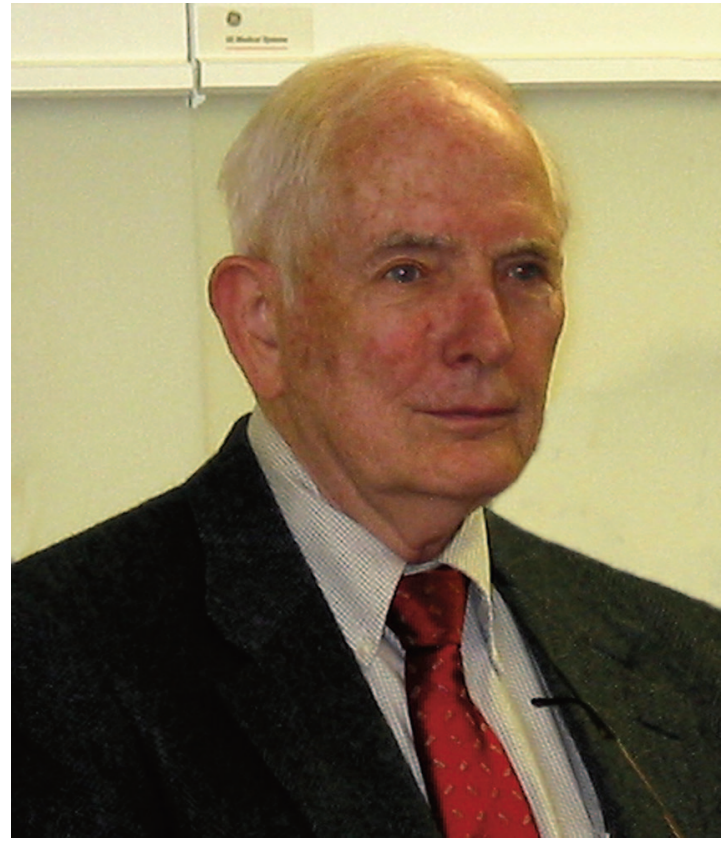

of University Radiologists and of the American Society of Neuroradiology. In 1975, he served on the Panel of Consultants to the Commission on CIA Activities within the United States, reviewing the assassination of President John F. Kennedy. He served for 21 years as a guest examiner for the American Board of Radiology.

Ted served as an attending physician in neuroradiology at Barnes-Jewish and St. Louis Children's hospitals and as a consultant to Barnes-Jewish West County and Barnes-Jewish St. Peters hospitals. Over the course of his 32 years at the Institute, Ted was a patient, enthusiastic, and generous teacher who enriched the careers of numerous fellows, residents, and medical students at Washington University Medical Center.

Ted Hodges was a gifted radiologist, a dedicated teacher, a dear friend to many, and a loving and devoted family man. $\mathrm{He}$ will be missed by everyone who was fortunate to have known him.

He is survived by his wife, Genny; 2 sons, Fred and Thomas; and a brother, John.

Franz J. Wippold

DOI 10.3174/ajnr.A0819 